\title{
(6) OPEN ACCESS \\ Physiological-based cord clamping in preterm infants using a new purpose-built resuscitation table: a feasibility study
}

\author{
Emma Brouwer, ${ }^{1}$ Ronny Knol, ${ }^{1,2}$ Alex S N Vernooij, ${ }^{3}$ Thomas van den Akker, ${ }^{4}$ \\ Patricia E Vlasman, ${ }^{1}$ Frans J C M Klumper, ${ }^{\oplus}{ }^{4}$ Philip DeKoninck, ${ }^{5,6}{ }^{\text {Graeme R Polglase, }}{ }^{6}$ \\ Stuart B Hooper, ${ }^{6}$ Arjan B te Pas ${ }^{1}$
}

\begin{abstract}
'Division of Neonatology, Department of Paediatrics, Leiden University Medical Centre, Leiden, The Netherlands 2Division of Neonatology, Department of Paediatrics, Erasmus University Medical Centre, Rotterdam, The Netherlands

${ }^{3}$ Department of Medical Engineering, Leiden University Medical Centre, Leiden, The Netherlands

${ }^{4}$ Department of Obstetrics, Leiden University Medical Centre, Leiden, The Netherlands ${ }^{5}$ Department of Obstetrics and Gynaecology, Erasmus University Medical Centre, Rotterdam, The Netherlands ${ }^{6}$ The Ritchie Centre, Hudson Institute of Medical Research, Monash University, Clayton, Victoria, Australia
\end{abstract}

\section{Correspondence to} Neonatology, Department of Paediatrics, Leiden University Medical Centre, Leiden 2300RC, The Netherlands;

e.brouwer@lumc.nl

EB and RK contributed equally.

Received 7 May 2018 Revised 6 September 2018 Accepted 9 September 2018 Published Online First 3 October 2018
Emma Brouwer, Division of

\begin{abstract}
Objective Physiological-based cord clamping (PBCC) led to a more stable cardiovascular adaptation and better oxygenation in preterm lambs, but in preterm infants, this approach has been challenging. Our aim was to assess the feasibility of PBCC, including patterns of oxygen saturation $\left(\mathrm{SpO}_{2}\right)$ and heart rate $(\mathrm{HR})$ during stabilisation in preterm infants using a new purpose-built resuscitation table.

Design Observational study.

Setting Tertiary referral centre, Leiden University Medical Centre, The Netherlands.

Patients Infants born below 35 weeks' gestational age. Interventions Infants were stabilised on a new purpose-built resuscitation table (Concord), provided with standard equipment needed for stabilisation. Cord clamping was performed when the infant was stable (HR > 100 bpm, spontaneous breathing on continuous positive airway pressure with tidal volumes $>4 \mathrm{~mL} / \mathrm{kg}$, $\mathrm{SpO}_{2} \geq 25$ th percentile and fraction of inspired oxygen $\left.\left(\mathrm{FiO}_{2}\right)<0.4\right)$.
\end{abstract}

Results Thirty-seven preterm infants were included; mean (SD) gestational age of 30.9 (2.4) weeks, birth weight 1580 (519) g. PBCC was successful in 33 infants $(89.2 \%)$ and resulted in median (IQR) cord clamping time of 4:23 (3:00-5:11) min after birth. There were no maternal or neonatal adverse events. In 26/37 infants, measurements were adequate for analysis. HR was 113 (81-143) and 144 (129-155) bpm at $1 \mathrm{~min}$ and $5 \mathrm{~min}$ after birth. $\mathrm{SpO}_{2}$ levels were $58 \%(49 \%-60 \%)$ and $91 \%(80 \%-96 \%) \%)$, while median $\mathrm{FiO}_{2}$ given was 0.30 (0.30-0.31) and $0.31(0.25-0.97)$, respectively. Conclusion $\mathrm{PBCC}$ in preterm infants using the Concord is feasible. $\mathrm{HR}$ remained stable, and $\mathrm{SpO}_{2}$ quickly increased with low levels of oxygen supply.

Trial registration number NTR6095, results.

\section{Check for updates}

(C) Author(s) (or their employer(s)) 2019. Re-use permitted under CC BY-NC. No commercial re-use. See rights and permissions. Published by BMJ.

To cite: Brouwer E, Knol R, Vernooij ASN, et al. Arch Dis Child Fetal Neonatal Ed 2019:104:F396-F402.

\section{INTRODUCTION}

Multiple trials in preterm infants have shown that delayed umbilical cord clamping (DCC), as compared with immediate umbilical cord clamping (ICC), reduces the risk of mortality and the need for blood transfusions. ${ }^{1} 2$ The mechanism of increased survival is not fully understood; however, the beneficial effect of DCC mainly was attributed to a larger circulating neonatal blood volume by increased placental transfusion. ${ }^{3}$ Preterm infants requiring stabilisation or resuscitation at birth were

\section{What is already known on this topic?}

Preterm infants requiring stabilisation or resuscitation are excluded from the beneficial effects of delayed cord clamping.

- Clinical approaches in providing respiratory support prior to cord clamping still used a fixed time point for clamping.

- Changes in heart rate and oxygen saturation of preterm infants before cord clamping are currently unknown.

\section{What this study adds?}

Physiological-based cord clamping using a new purpose-built resuscitation table is feasible and without adverse events for mother and infant.

- Using the infant's condition and transitional status as key determinant for the timing of cord clamping results in considerably later cord clamping than described previously.

- Physiological-based cord clamping is associated with stable heart rate and improved oxygen saturation during transition in preterm infants.

generally excluded from DCC and received ICC, because of the necessity to transfer these infants to a resuscitation table to provide respiratory support.

While it is recognised that the pulmonary and haemodynamic transitions at birth are intimately linked ${ }^{45}$ current clinical practice recommends cord clamping at a fixed time point, irrespective of the infant's transitional status. ICC can cause a sudden reduction in cardiac output, heart rate (HR) and blood pressure, whereas cord clamping after onset of ventilation (physiological-based cord clamping (PBCC)) avoids both this and the large disturbances in systemic and cerebral haemodynamics in experimental settings. ${ }^{5} 6$ These findings may explain the bradycardia and hypoxaemia that are often observed in preterm infants after cord clamping. ${ }^{7-9}$ Therefore, a more physiological approach to the timing of cord clamping is likely to be beneficial. Particularly preterm infants may benefit from this approach since large fluctuations in tissue oxygenation and perfusion increase the risk of mortality and morbidity. ${ }^{10}$ 
Recent studies investigating providing respiratory support in preterm infants with an intact umbilical cord deemed the procedure feasible. ${ }^{11-13}$ Although these studies monitored respiratory effort, $\mathrm{HR}$ and oxygen saturation $\left(\mathrm{SpO}_{2}\right)$, these parameters were only measured after cord clamping. Moreover, the timing of cord clamping was always done at a fixed time point. We postulate that including the transitional status of the preterm infant as a key determinant for the timing of cord clamping may result in optimised cord clamping.

To enable PBCC in preterm infants, a new purpose-built resuscitation table (the Concord) was designed in a collaborative initiative of the Neonatal, Obstetric and Medical Engineering Departments of Leiden University Medical Centre (LUMC), according to the following criteria: (1) ability to provide full standard care for preterm stabilisation, (2) ability to monitor the infant, (3) prevention of kinking and stretching of the umbilical cord and (4) ability to proceed unhindered care for the mother. The aim of this study was to assess feasibility of the PBCC approach in preterm infants using this novel device.

\section{METHODS}

We performed a prospective observational feasibility study at the LUMC from October 2016 to November 2017. The study was registered in the Netherlands National Trial Register (NTR6095), and Institutional Review Board approval (P16.146) was obtained prior to starting the study. An external safety board was not installed.

\section{Study population}

Infants were included if they were born between 26 and 35 weeks of gestational age (GA), and no complications other than preterm birth were expected. Informed consent was requested of all pregnant women who had been admitted to the obstetric department in our institution for imminent preterm birth. Inclusion started with preterm infants born between 30 weeks and 35 weeks of gestation. After including eight infants without any problems, we proceeded to include infants born between 26 weeks' gestation and 35 weeks' gestation. Initially, only infants born vaginally could be included, as precautions concerning sterility of the procedure in the operating room were still in progress. After 6 months of gaining experience and taking the appropriate precautions, infants born after caesarean section were included as well. Exclusion criteria were signs of placental abruption or placenta praevia, signs of severe fetal distress determined by the clinician and the necessity for an emergency caesarean section ordered to be executed within $15 \mathrm{~min}$. In this feasibility study, the predefined goal was to include a total minimum of 16 infants, a minimum of 8 infants in both GA groups and a minimum of 5 infants born after caesarean section. All infants of parents who had consented to participate were allowed to be included even though the convenience sample was reached, which is why the final number exceeds our predefined samples.

\section{Equipment}

A new custom-designed resuscitation table (the Concord, figure 1) was used to provide full standard of care for stabilisation of preterm infants at birth with an intact umbilical cord. The Concord is a mobile device, of which the platform can be adjusted to be positioned in very close proximity to the birth canal without stretching the umbilical cord. The platform contains a slit through which the umbilical cord can be placed. The table is provided with the same equipment for resuscitation as used in our standard resuscitation table, being a T-piece ventilator, radiant warmer, suctioning device,

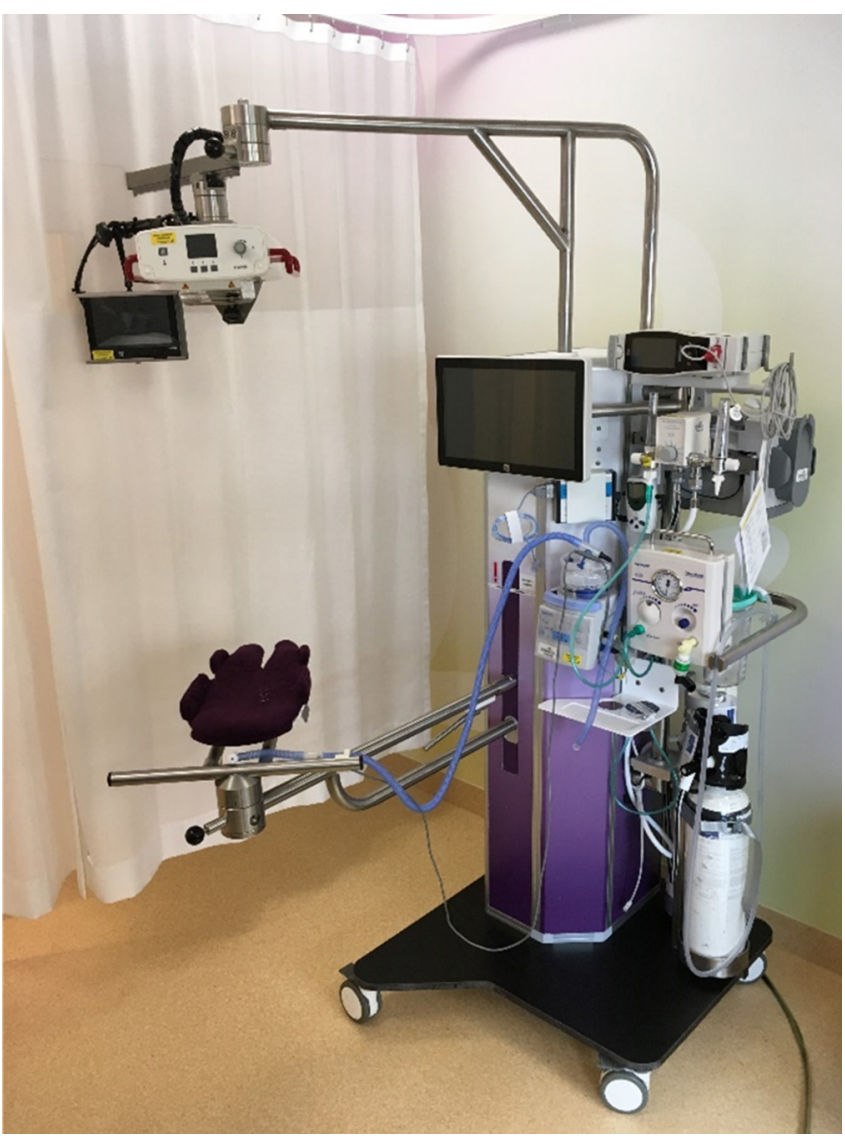

Figure 1 The Concord, a new specially designed resuscitation table, including the platform for the infant, which can be turned above the mother's pelvis. The table is fully equipped to provide complete standard care and has a built-in respiratory function monitor.

oxygen blender, heater and humidifier, and a heated resuscitation circuit. In addition, the Concord contains a respiratory function monitor (NewLifeBox Neo-RSD computer system; Advanced Life Diagnostics, Weener, Germany), depicting respiratory function, $\mathrm{SpO}_{2}, \mathrm{HR}$ and fraction of inspired oxygen $\left(\mathrm{FiO}_{2}\right)$, as well as a video camera (Applied Biosignals, Weener, Germany). We obtained $\mathrm{SpO}_{2}$ and HR measurements using a pulse oximeter (Masimo Radical, Masimo Corporation, Irvine, California, USA). All resuscitation procedures were video recorded as is customary at our institution. The signals were digitised at $200 \mathrm{~Hz}$ using the NewLifeBox -R physiological recording system (Advanced Life Diagnostics) supported by Polybench physiological software (Applied Biosignals).

\section{Procedure}

Prior to the start of the study all caregivers involved in labour care were trained in using the Concord, for which a standard operating procedure was written. All neonatal caregivers were trained and accredited for neonatal resuscitation. After each procedure details of birth and aspects of stabilisation were evaluated with the staff involved. Any safety issues or problems reported during the evaluation would be resolved before the next infant would be included.

The Concord was placed next to the woman's bed before progression to the second stage of labour or next to the theatre table prior to the start of caesarean section. All equipment was checked and set up in advance. The standard resuscitation table and equipment were also prepared as fall back option. If the attending neonatologist or obstetrician considered that $\mathrm{PBCC}$ 
should not be performed or interrupted, the infant would be taken to the standard resuscitation table for (further) stabilisation.

The time of birth was defined as the moment when the infant was completely out of the birth canal. At this moment, the timer was started. To enable PBCC. the obstetrician held the infant after birth, and the woman was asked to lower her left leg. The platform of the Concord was then placed above the woman's pelvis as close as possible to the birth canal to ensure that the umbilical cord was not stretched. The infant was placed on the platform and received stabilisation and heat loss prevention according to standard guidelines by the neonatal team, while the obstetrician assessed maternal condition and checked that the umbilical cord was not stretched nor kinked. After a vaginal delivery, parents were encouraged to touch and stimulate the infant during stabilisation. Infants were stabilised following the institutional newborn resuscitation guideline, starting with heat loss prevention, adequate positioning and tactile stimulation. Face mask ventilation breaths or sustained inflations were applied to inadequately breathing infants (initial $\mathrm{FiO}_{2}: 21 \%-30 \%$ ), followed by continuous positive airway pressure (CPAP) or a period of positive pressure ventilation (PPV) if necessary. Surfactant was not administered in the delivery room. As soon as the infant was considered stable, defined as the establishment of adequate breathing (average tidal volume $\geq 4 \mathrm{~mL} / \mathrm{kg}$ ) on CPAP, HR above $100 \mathrm{bpm}$ and $\mathrm{SpO}_{2}$ above 25 th percentile using $\mathrm{FiO}_{2}<0.4$, the cord was clamped. Uterotonic drugs were administered immediately after cord clamping. Subsequently, the platform was pulled back and placed next to the bed of the woman, enabling physical contact with her infant. The infant was then transferred to the transport incubator and transported to the neonatal intensive care unit (NICU).

In case of twin birth, clamping of the first infant was performed according to PBCC or earlier if the second infant was about to be born. After clamping, the first infant was transferred to a standard resuscitation table, so the second infant could be stabilised using the Concord. Only the second infant was stabilised using the Concord when twins were born after caesarean section, due to logistical reasons.

The PBCC approach would be aborted immediately in case of: (1) the maternal condition requiring more work space for the obstetrical team, (2) full cardiac resuscitation of the infant or (3) excessive maternal blood loss as determined by the obstetrical team.

\section{Outcome and safety parameters}

The primary outcome was the ability to perform PBCC. Secondary outcomes were timing of cord clamping, HR and $\mathrm{SpO}_{2}$ in the first $10 \mathrm{~min}$ of life and important safety parameters: maternal blood loss, infant temperature at NICU admission and the incidence of polycythaemia or severe hyperbilirubinaemia requiring exchange transfusion. Maternal and infant baseline characteristics and short-term outcomes were collected.

Measurements of $\mathrm{HR}, \mathrm{SpO}_{2}$ and $\mathrm{FiO}_{2}$ were obtained every $0.5 \mathrm{~s}$ and automatically averaged over a $2 \mathrm{~s}$ interval by pulse oximeter. Measurements were obtained until $10 \mathrm{~min}$ after delivery of the neonate. Data points were analysed if a good quality pulse oximeter signal was obtained without any alarm messages (low identification, low perfusion index and sensor off). HR and $\mathrm{SpO}_{2}$ measurements are displayed per minute, presented as median (IQR), starting from the first minute after birth. All measurements were averaged over a $6 \mathrm{~s}$ period around every whole minute. Measurements on $\mathrm{HR}$ and $\mathrm{SpO}_{2}$ are specifically reported for infants born $<32$ weeks' GA, as these infants

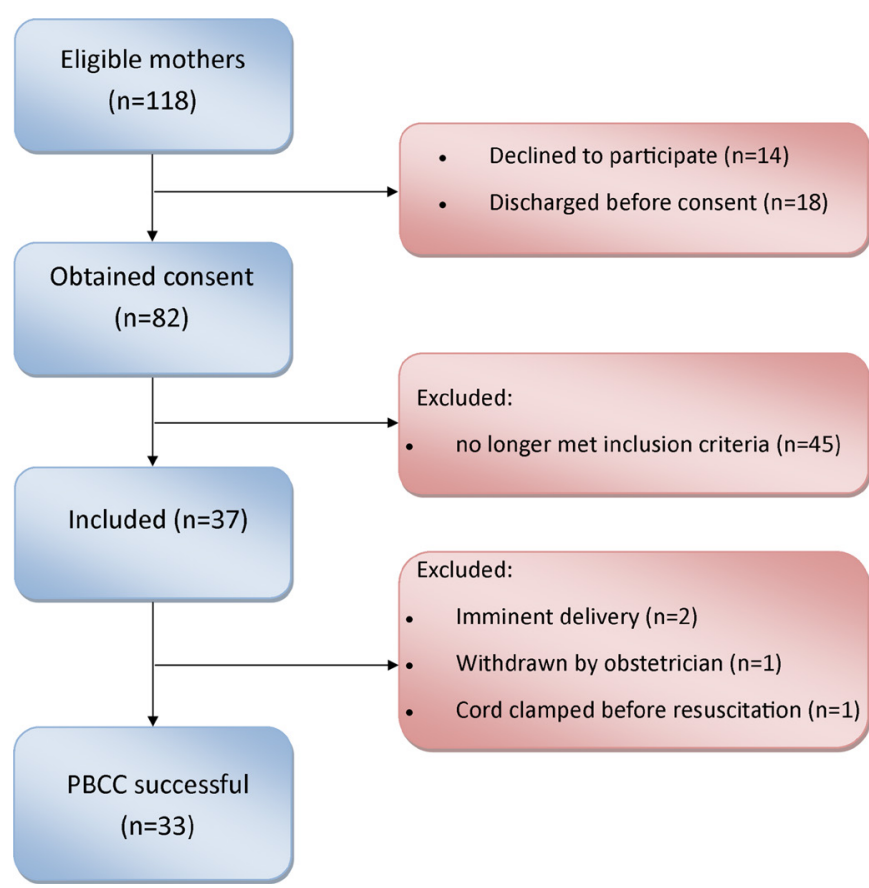

Figure 2 CONSORT diagram. CONSORT, Consolidated Standards of Reporting Trials; PBCC, physiological-based cord clamping.

are most in need of resuscitation, and this GA group is most commonly used in literature.

HR measurements obtained around the time of cord clamping were reviewed (from $10 \mathrm{~s}$ before to $30 \mathrm{~s}$ after umbilical cord clamping). Additionally, we calculated the occurrence and proportion of time $\mathrm{SpO}_{2}$ measurements were below, within and above target ranges only for infants born $<32$ weeks' GA, as defined by White et al. More specifically, at 3-4 min, 4-5 min and $5-10 \mathrm{~min}$, the corresponding $\mathrm{SpO}_{2}$ target ranges were 70\%-90\%, 75\%-90\% and 80\%-90\%, respectively. ${ }^{7}$

\section{Statistical analysis}

Data were analysed using IBM SPSS Statistic V.24.0 software. Normally distributed data are presented as mean \pm SD, not-normally distributed data as median (IQR). Pearson correlation test was used to test associations between continuous variables. Friedmans analysis was performed to test for differences between measurements over a time period. Graphs were designed using GraphPad Prism 7.

\section{RESULTS}

A total of 118 parent couples were approached for study participation of which 82 couples consented. Thirty-seven infants were included (figure 2) with a mean GA of $30.9 \pm 2.4$ weeks. Baseline characteristics are shown in table 1 .

\section{Perinatal outcomes}

PBCC was successful in 33 infants (89.2\%, table 2) but was not performed in four infants for three reasons: (1) in two births the neonatal team arrived too late in the labour room to use the Concord and perform PBCC; (2) in one birth the umbilical cord was too short and had to be clamped immediately; and (3) in one birth the attending obstetrician had clinical concerns to perform PBCC (figure 2). We observed a median (IQR) cord clamping time of $4: 23(3: 00-5: 11)$ min after birth (vaginal birth $4: 20$ $(2: 55-5: 11) \mathrm{min}$ and caesarean section $4: 49$ (3:56-5:37) min). 


\begin{tabular}{ll}
\hline Table 1 Baseline characteristics & \\
\hline Characteristics & All infants $(\mathbf{n}=37)$ \\
\hline Gestational age, weeks & $30.9 \pm 2.4$ \\
\hline Gestational age, range & $26.3-35.9$ \\
\hline Gestational age (weeks) & \\
\hline $32-35$ & $11(29.7)$ \\
\hline $30-32$ & $15(40.5)$ \\
\hline 26-30 & $11(29.7)$ \\
\hline Birth weight, g & $1580 \pm 519$ \\
\hline Male & $19(51.4)$ \\
\hline Twins (number of infants) & $11(29.7)$ \\
\hline Maternal age, year & $30.7 \pm 3.9$ \\
\hline Pre-eclampsia/HELLP & $8(21.6)$ \\
\hline Chorioamnionitis & $7(18.9)$ \\
\hline Antenatal steroids & $19(51.4)$ \\
\hline Complete (>48hours) & $15(40.5)$ \\
\hline Partly (0-48hours) & $3(8.1)$ \\
\hline No & $8(21.6)$ \\
\hline Caesarean section &
\end{tabular}

Data are presented as mean \pm SD and $\mathrm{n}(\%)$.

HELLP, haemolysis, elevated liver enzymes, low platelet syndrome.

Most infants (94.6\%) received respiratory support for stabilisation. No infant needed intubation or surfactant during stabilisation. Further details on perinatal outcomes are presented in table 2. There was no significant correlation between the timing of cord clamping and GA $(r=-0.161 ; p=0.37)$, maternal blood loss $(\mathrm{r}=-0.119 ; \mathrm{p}=0.52)$ or infant admission temperature $(r=-0,157 ; p=0.38)$.

\section{Physiological parameters}

Due to technical failure, measurements on $\mathrm{HR}, \mathrm{SpO}_{2}$ and $\mathrm{FiO}_{2}$ were not stored in 7 out of 33 infants. Therefore, physiological parameters could be analysed in 26 infants. The first reliable measurements were obtained at a median (IQR) time of $81.3(50.8-117.8) \mathrm{s}$ after birth. Measurements are reported for infants born $<32$ weeks' GA (measurements available for 20 out of 26 infants) and are listed for all infants in table 3.

\begin{tabular}{ll}
\hline Table 2 Perinatal outcomes & \\
\hline Perinatal outcome & All infants ( $\mathbf{n}=37$ ) \\
\hline PBCC performed & $33(89.2)$ \\
\hline Cord clamping time, min & $4: 23(3: 00-5: 11)$ \\
\hline Apgar score at $1 \mathrm{~min}$ & $7(5-8)$ \\
\hline Apgar score at $5 \mathrm{~min}$ & $8(8-9)$ \\
\hline Umbilical cord, $\mathrm{pH}$ & $7.25 \pm 0.10$ \\
\hline Respiratory support at birth & $35(94.6)$ \\
\hline CPAP & $35(94.6)$ \\
\hline PPV & $11(29.7)$ \\
\hline Intubation & 0 \\
\hline Maternal blood loss, $\mathrm{mL}$ & $300(200-475)$ \\
\hline Temperature at $\mathrm{NICU}$ admission, ${ }^{\circ} \mathrm{C}$ & $36.0 \pm 0.70$ \\
\hline Temperature $36.0^{\circ} \mathrm{C}-36.4^{\circ} \mathrm{C}$ & $8(21.6)$ \\
\hline Temperature $<36.0^{\circ} \mathrm{C}$ & $18(48.6)$ \\
\hline Haemoglobin $<24$ hours, $\mathrm{g} / \mathrm{dL}$ & $18.01 \pm 2.79$ \\
\hline Haematocrit $<24$ hours, $\%$ & $52.6 \pm 7.63$ \\
\hline
\end{tabular}

Data are presented as mean $\pm \mathrm{SD}$; median (IQR) and $\mathrm{n}(\%)$

CPAP, continuous positive airway pressure; $\mathrm{NICU}$, neonatal intensive care unit: PBCC, physiological-based cord clamping; PPV, positive pressure ventilation.

\begin{tabular}{|c|c|c|c|c|}
\hline Minutes & $\begin{array}{l}\text { HR }<32 \text { weeks } \\
\text { median (IQR), } \\
n=20\end{array}$ & $\begin{array}{l}\mathrm{SpO}_{2}<32 \text { weeks } \\
\text { median (IQR), } \\
\mathrm{n}=20\end{array}$ & $\begin{array}{l}\text { HR all infants } \\
\text { median (IQR), } \\
n=26\end{array}$ & $\begin{array}{l}\mathrm{SpO}_{2} \text { all infants } \\
\text { median (IQR), } \\
\mathrm{n}=26\end{array}$ \\
\hline 1 & $123(89-148)$ & $54(46-67)$ & $113(81-143)$ & $58(49-60)$ \\
\hline 2 & 127 (96-137) & $58(47-82)$ & $126(106-140)$ & 59 (49-81) \\
\hline 3 & $134(112-148)$ & 79 (57-91) & 135 (118-149) & $72(54-90)$ \\
\hline 4 & 141 (124-147) & 93 (78-95) & 141 (128-147) & 90 (65-94) \\
\hline 5 & 144 (128-155) & 92 (84-97) & 144 (129-155) & 91 (80-96) \\
\hline 6 & 143 (134-151) & 91 (88-96) & $143(135-151)$ & 91 (84-95) \\
\hline 7 & $146(131-155)$ & 91 (88-96) & $148(135-156)$ & 91 (87-95) \\
\hline 8 & 145 (132-151) & 93 (88-97) & 145 (127-151) & 93 (89-96) \\
\hline 9 & 144 (127-155) & 93 (90-96) & 145 (127-155) & 93 (90-96) \\
\hline 10 & 138 (129-155) & 92 (88-95) & 141 (129-155) & 93 (89-95) \\
\hline
\end{tabular}

Data are presented as median (IQR), for infants born $<32$ weeks of gestational age and all infants.

Median (IQR) HR for infants born <32 weeks' GA was 123 $(89-148), 127$ (96-137), $134(112-148)$ and $144(128-155)$ at 1 , 2,3 and 5 min after birth (figure $3 \mathrm{~A}$, table 3 ). One infant experienced an $\mathrm{HR}<60 \mathrm{bpm}$ at the third minute, which occurred simultaneously with mask reposition and was thought to be the effect of the nasal trigeminal reflex. Median (IQR) HR at time of cord clamping was 139 (127-151) bpm, and Friedmans analysis showed no significant changes in HR before, during or after cord clamping, $\chi^{2}(2)=0.000, p=1.000$ (figure $3 \mathrm{~B}$ ).

Measurements for median (IQR) $\mathrm{SpO}_{2}$ were 54\% (46\%-67\%), $58 \%(47 \%-82 \%), 79 \%(57 \%-91 \%) \%)$ and $92 \%(84 \%-97 \%) \%)$ at $1,2,3$ and $5 \mathrm{~min}$ (figure $3 \mathrm{C}$, table 3 ), while median (IQR) $\mathrm{FiO}_{2}$ given was $0.30(0.30-0.31), 0.30(0.30-0.31), 0.31(0.29-$ 0.51 ) and 0.31 (0.25-0.97), respectively. At periods 3-4 min, 4-5 $\mathrm{min}$ and $5-10 \mathrm{~min}$ proportions of time spent below the $\mathrm{SpO}_{2}$ 'target range' for infants born $<32$ weeks' GA were $25.3 \%$, $15.9 \%$ and $2.3 \%$ with administered median (IQR) $\mathrm{FiO}_{2}$ of 0.32 $(0.28-0.75), 0.31(0.27-0.79)$ and $0.31(0.26-0.48)$. Proportion of time spent above $\mathrm{SpO}_{2}$ value of $95 \%$ were $7.4 \%, 22.1 \%$ and $30.1 \%$, respectively (table 4 ).

\section{Clinical outcomes}

Short-term clinical outcomes are summarised in table 5. The majority of infants received phototherapy for hyperbilirubinaemia; none of the neonates needed exchange transfusion. Three infants $(8.1 \%)$ met the criteria of polycythaemia.

\section{DISCUSSION}

This is the first clinical study performing $\mathrm{PBCC}$ in preterm infants, using the infant's transitional status as the key determinant to direct the timing of cord clamping. Our results demonstrated that PBCC, when using the Concord, is feasible in a large majority of infants (89\%). All failures occurred at the beginning of our project, suggesting a learning curve for involved caretakers in timely being prepared for the procedure and in adequately positioning the Concord. Feasibility was good when compared with recent studies (ranging from 59\% to 100\%) where respiratory support was started before cord clamping though using a different set-up. ${ }^{11-13}$ International guidelines recommend delaying cord clamping for at least $30-60 \mathrm{~s}$ in stable preterm infants and immediate cord clamping for compromised infants. ${ }^{14}$ All recent studies providing respiratory support prior to cord clamping used time based cord clamping at $60-120 \mathrm{~s}^{11-13}$ Our PBCC approach led to considerably later cord clamping than reported in these studies using fixed time points, so infants 
A

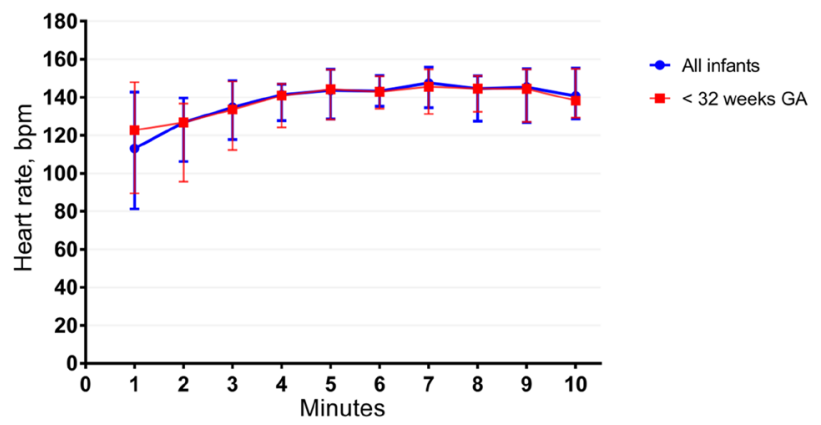

B

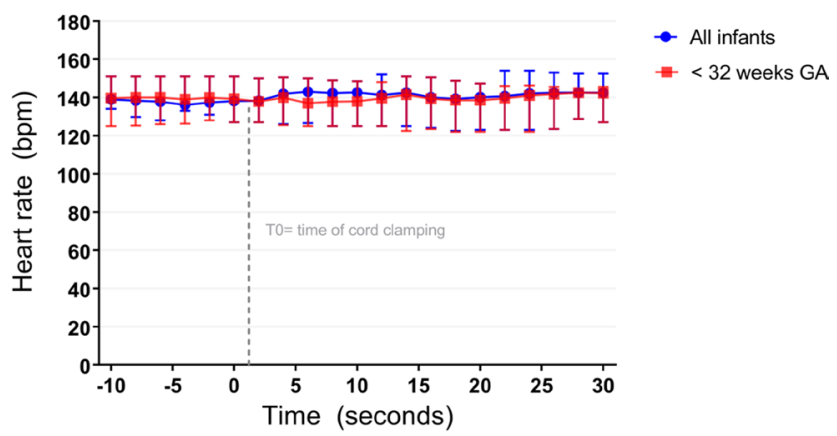

C

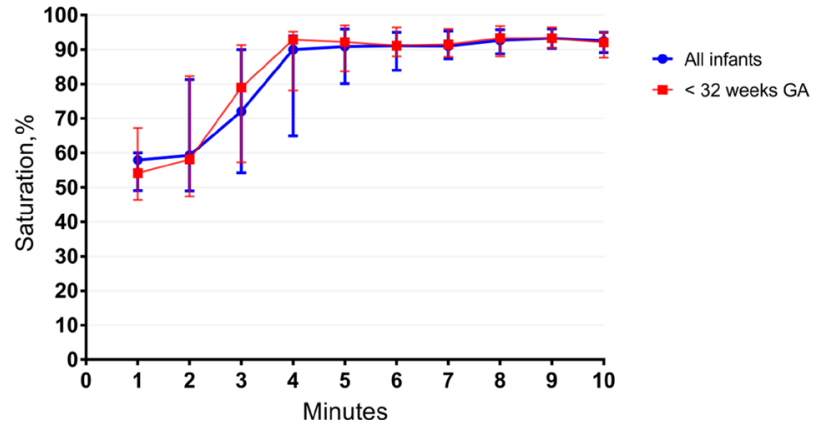

Figure 3 (A) Heart rate in the first 10 min after birth. Heart rate (bpm) is presented as median (IQR) for all infants and infants born $<32$ weeks of gestational age (GA). (B) Heart rate during cord clamping. Heart rate is displayed as median (IQR) in the period ranging from $10 \mathrm{~s}$ prior to and $30 \mathrm{~s}$ after umbilical cord clamping. Friedmans analysis showed no significant changes in HR before, during or after cord clamping (for all infants $\chi^{2}(2)=0.306, p=0.858$ and for infants born $<32$ weeks' GA, $\chi^{2}(2)=0.000, P=1.000$ ). (C) Oxygen saturation in the first $10 \mathrm{~min}$ after birth. Oxygen saturation is presented as median (IQR) for all infants and infants born $<32$ weeks of $\mathrm{GA}$.

potentially received a more complete placental transfusion. Yao et al demonstrated this would take at least 3 min. ${ }^{15}$ Moreover, the Concord made it possible for infants needing respiratory support to benefit from delaying cord clamping.
Table 5 Short-term neonatal clinical outcomes

\begin{tabular}{lc}
\hline Clinical outcomes & All infants $(\mathbf{n}=37)$ \\
\hline IRDS & $8(21.6)$ \\
\hline Surfactant therapy & $7(18.9)$ \\
\hline Respiratory support $<72$ hours & $28(75.7)$ \\
\hline Nasal cannula & 0 \\
\hline CPAP/High flow & $23(62.2)$ \\
\hline Invasive ventilation & $5(13.5)$ \\
\hline Inotropes $<72$ hours & $2(5.4)$ \\
\hline PDA diagnosed & $7(18.9)$ \\
\hline Treated & $5(13.5)$ \\
\hline NEC $\geq$ stage 2 & $3(8.1)$ \\
\hline Late onset infection & $11(29.7)$ \\
\hline Hyperbilirubinaemia & \\
\hline Phototherapy & $35(94.6)$ \\
\hline Exchange transfusion & 0 \\
\hline Erythrocyte transfusion & $7(18.9)$ \\
\hline Polycythaemia & $3(8.1)$ \\
\hline IVH & $5(13.5)$ \\
\hline Grade 1 & $2(5.4)$ \\
\hline Grade 2 & $1(2.7)$ \\
\hline Grade 3 & $2(5.4)$ \\
\hline Venous infarction & $1(2.7)$ \\
\hline Ventricular dilatation & $1(2.7)$ \\
\hline ROP & $4(10.8)$ \\
\hline Grades 1-2 & $4(10.8)$ \\
\hline Grades 3-4 & 0 \\
\hline BPD & $3(8.1)$ \\
\hline Mild & 0 \\
\hline Moderate & 0 \\
\hline Severe & $3(8.1)$ \\
\hline Da a & \\
\hline
\end{tabular}

Data are presented as $n(\%)$.

$\mathrm{BPD}$, bronchopulmonary dysplasia; CPAP, continuous positive airway pressure; IRDS, infant respiratory distress syndrome; IVH, intraventricular haemorrhage; NEC, necrotising enterocolitis; PDA, persistent ductus arteriosus; ROP, retinopathy of prematurity.

This is the first study to record physiological parameters $\mathrm{HR}$ and $\mathrm{SpO}_{2}$ continuously in the first minutes of life when performing PBCC in preterm infants. Previous studies have investigated the effects of ventilation prior to cord clamping, ${ }^{11-13}$ but $\mathrm{HR}$ and $\mathrm{SpO}_{2}$ were either not reported or were not recorded continuously, making it difficult to compare our findings with the literature. We observed that the HR of (very) preterm infants were higher and more stable than described so far for other methods of cord clamping. ${ }^{716}$ In addition, no bradycardia was observed after umbilical cord clamping. Recent studies have described that bradycardia often occurs in the first minutes after birth when immediate or DCC is performed. ${ }^{76} 17$ Indeed,

Table 4 Proportion of time spent within, below or above oxygen saturation $\left(\mathrm{SpO}_{2}\right.$ ) target ranges, listed as percentages (all infants born $<32$ weeks' gestational age: $n=20$ ), proportion of time was calculated over 2280 measurements for $3-4$ min and 4-5 min, and over 11400 measurements for $5-10 \mathrm{~min}$

\begin{tabular}{|c|c|c|c|c|c|c|c|}
\hline Time after birth & $\mathrm{SpO}_{2}$ target & $\begin{array}{l}\text { Proportion of time } \\
\text { below target (\%) }\end{array}$ & $\begin{array}{l}\text { Proportion of time } \\
\text { within target (\%) }\end{array}$ & $\begin{array}{l}\text { Proportion of time } \\
\text { above target (\%) }\end{array}$ & Missing values (\%) & $\begin{array}{l}\mathrm{SpO}_{2} \text { median } \\
\text { (IQR) }\end{array}$ & $\begin{array}{l}\text { Fraction of } \\
\text { inspired oxygen } \\
\text { median (IQR) }\end{array}$ \\
\hline $3-4 \min$ & $70-90$ & 25.3 & 34.3 & 31.6 & 8.8 & 87 (67-92) & $0.32(0.28-0.75)$ \\
\hline $4-5 \min$ & $75-90$ & 15.9 & 21.8 & 55.1 & 7.2 & 93 (84-95) & $0.31(0.27-0.97)$ \\
\hline 5-10 min & $80-90$ & 2.3 & 28.9 & 57.2 & 10.7 & $93(88-96)$ & $0.31(0.26-0.48)$ \\
\hline
\end{tabular}


White et al observed bradycardia in more than $50 \%$ of infants at $2 \mathrm{~min}$ after delivery, suggested by their median (IQR) HR of 88 (71-147) after immediate cord clamping. In our cohort, we rarely observed bradycardia (HR 123 (89-148)) and interestingly $\mathrm{HR}$ also remained stable around the moment of cord clamping. ${ }^{7}$ This suggests that cardiac output depended to a lesser extent on placental venous return, while pulmonary blood flow had successfully increased to compensate. It is striking that the HR was higher and the rate of increase was less steep in the first 2 min compared with the nomogram of preterm infants who needed no support and were $<37$ weeks of GA but received ICC. ${ }^{16}$ These observations correspond with the results of the experimental PBCC studies and imply that the preterm infants were haemodynamically stable, with a gradual transition and without adverse events. ${ }^{45}$

Median $\mathrm{SpO}_{2}$ of the infants in our study increased quickly in the first $4 \mathrm{~min}$ after birth to a stable level above $90 \%$, while there was very little change in the median $\mathrm{FiO}_{2}$. Median $\mathrm{SpO}_{2}$ increased at a faster pace than previously described for preterm infants in whom ICC was performed. Duration of hypoxaemia was shorter at lower levels of oxygen supply within the first 10 min. $^{78} 18$ Avoiding hypoxaemia, especially in the first minutes after birth, is pivotal since this is associated with lower HR and increased risk of intraventricular haemorrhage and death. ${ }^{19}$ In addition, the occurrence of hypoxaemia and bradycardia would often lead to more vigorous PPV, which can be associated with increased morbidity. Mian et al recently demonstrated that delivery of high tidal volume is associated with intraventricular haemorrhage. ${ }^{20}$ Although our infants spent a greater proportion of time above the $\mathrm{SpO}_{2}$ target ranges when compared with White et al, only a small proportion had $\mathrm{SpO}_{2}$ values $>95 \%$ while lower levels of additional oxygen were given.

Clamping the umbilical cord without the occurrence of bradycardia and decreasing the duration of hypoxaemia is likely to be the effect of haemodynamic stability created by PBCC. Clamping the umbilical cord after lung aeration avoids decrease in left ventricular output, seen after immediate cord clamping, since the source of preload can easily switch from umbilical to pulmonary venous return. ${ }^{21}{ }^{22}$ Furthermore, the increase in afterload seen after ICC, due to loss of the placenta's low vascular resistance, is greatly mitigated during PBCC since the pulmonary circulation becomes an alternative route for systemic blood flow through the ductus arteriosus. ${ }^{23}{ }^{24}$ This results in the preservation of stable cardiac output and therefore a stable supply of oxygenated blood, which explains the higher $\mathrm{SpO}_{2}$ values and absence of bradycardia after PBCC. Acknowledging that these observations are derived from experimental animal-based research, we think our results trigger further and ongoing collection of human data concerning primary physiological changes during newborn transition. ${ }^{25}$

No serious adverse events regarding the Concord or the PBCC procedure were reported during the study. Maternal blood loss and the incidence of polycythaemia were within normal ranges and were not associated with duration of cord clamping. ${ }^{26} 27$ All infants born before 32 weeks of gestation needed phototherapy, but no exchange transfusion was required. A potential draw back was the mean infant temperature at NICU admission of $36.0^{\circ} \mathrm{C}$ (range $34.5^{\circ} \mathrm{C}-37.6^{\circ} \mathrm{C}$ ). Although comparable with temperatures reported in some previous DCC studies, ${ }^{2829}$ heat loss prevention using the Concord was an important focus. During our project, extra effort was undertaken in additional education for involved caretakers to decrease the incidence of hypothermia, especially in infants delivered via caesarean section as they experienced more hypothermia. This was established by early activation of the radiant heater, thus adequately prewarming the platform and adjusting room temperature in the operating theatre. Furthermore, the incidence of NEC in our cohort was higher than expected, mainly due to monochorionic twins of 32 weeks' GA both experiencing NEC stage 2a, recovering without surgery. Interestingly, two out of the three infants experiencing NEC did not receive PBCC and were clamped early.

Although the study was not powered for physiological measurements, and measurements were available in only 26 out of 37 infants, IQR for most measurements were small indicating little variability between individuals; therefore, one could conclude that this represents a good estimation of $\mathrm{HR}$ and $\mathrm{SpO}_{2}$ during PBCC. Although various studies have demonstrated electrocardiogram (ECG) to give a more rapid and accurate measure of HR, ${ }^{3031}$ the use of pulse oximeter in our study was for pragmatic reasons. Whether it is better to use ECG (electrical activity) or pulse oximeter (pulse wave, indication that electrical activity is followed by a pulse wave arriving in the peripheral circulation), remains open for debate. Variation between measurements was largest in the first $3 \mathrm{~min}$ after birth, which is consistent with current reference ranges. ${ }^{1632}$ This was a single-centre study, and a subsequent larger multicentre randomised controlled trial is planned. This will enable us to evaluate effectiveness of PBCC in other centres and compare data with a control group.

In summary, considering the success percentage in performing PBCC, a more stable HR and faster increase in oxygenation and the absence of reported serious adverse events, we consider the PBCC approach in preterm infants using the Concord feasible. This report is the first to describe real-time monitoring of HR and $\mathrm{SpO}_{2}$ during $\mathrm{PBCC}$ in very preterm infants, and measurements provide human data that seem to support most of the experimental findings. Importantly, HR remained stable around cord clamping, which makes it likely that PBCC may result in optimal timing of cord clamping and in optimal pulmonary and cardiovascular transition. Further physiological research and larger randomised clinical studies are required to establish effectiveness of PBCC in improving clinical benefits in this challenging group of infants.

Contributors EB, RK and ABtP wrote the ethics application, participated in the study design and coordination, trained the clinicians, collected and analysed the data and reviewed the literature. ASNV, FJCMK and SBH participated in the study design. $\mathrm{EB}, \mathrm{RK}, \mathrm{ASNV}, \mathrm{FJCMK}, \mathrm{ABtP}, \mathrm{SBH}$ and PEV participated in design and development of the device. EB and RK wrote the first draft and submitted the article. All authors participated in reviewing the data and editing the manuscript. All authors have read and approved the final manuscript.

Funding $A B+P$ is recipient of an NWO (Netherlands Organisation for Scientific Research) innovational research incentives scheme (VIDI 91716428). This project was sponsored by the Gisela Thier Fund (Leiden) and the Sophia Children's Hospital Foundation (Rotterdam).

Competing interests None declared.

Patient consent Parental/guardian consent obtained.

Ethics approval Commissie Medische Ethiek van het Leids Universitair Medisch Centrum.

Provenance and peer review Not commissioned; externally peer reviewed.

Open access This is an open access article distributed in accordance with the Creative Commons Attribution Non Commercial (CC BY-NC 4.0) license, which permits others to distribute, remix, adapt, build upon this work non-commercially, and license their derivative works on different terms, provided the original work is properly cited, appropriate credit is given, any changes made indicated, and the use is non-commercial. See: http://creativecommons.org/licenses/by-nc/4.0/.

\section{REFERENCES}

1 Fogarty M, Osborn DA, Askie L, et al. Delayed vs early umbilical cord clamping for preterm infants: a systematic review and meta-analysis. Am J Obstet Gynecol 2018;218:1-18. 
2 Rabe H, Diaz-Rossello JL, Duley L, et al. Effect of timing of umbilical cord clamping and other strategies to influence placental transfusion at preterm birth on maternal and infant outcomes. Cochrane Database Syst Rev 2012;8:CD003248.

3 Katheria AC, Lakshminrusimha S, Rabe $\mathrm{H}$, et al. Placental transfusion: a review. J Perinatol 2017;37:105-11.

4 Bhatt S, Alison BJ, Wallace EM, et al. Delaying cord clamping until ventilation onset improves cardiovascular function at birth in preterm lambs. J Physiol 2013;591:2113-26.

5 Polglase GR, Dawson JA, Kluckow M, et al. Ventilation onset prior to umbilical cord clamping (physiological-based cord clamping) improves systemic and cerebral oxygenation in preterm lambs. PLOS One 2015;10:e0117504.

6 Blank DA, Polglase GR, Kluckow M, et al. Haemodynamic effects of umbilical cord milking in premature sheep during the neonatal transition. Arch Dis Child Fetal Neonatal Ed 2018;104:F539-46

7 White $\mathrm{LN}$, Thio M, Owen LS, et al. Achievement of saturation targets in preterm infants $<32$ weeks' gestational age in the delivery room. Arch Dis Child Fetal Neonatal Ed 2017:102:F423-F7.

8 Goos TG, Rook D, van der Eijk AC, et al. Observing the resuscitation of very preterm infants: are we able to follow the oxygen saturation targets? Resuscitation 2013;84:1108-13

9 Phillipos E, Solevag AL, Aziz K, et al. Oxygen saturation and heart rate ranges in very preterm infants requiring respiratory support at birth. J Pediatr 2017;182:41-6.

10 Polglase GR, Miller SL, Barton SK, et al. Respiratory support for premature neonates in the delivery room: effects on cardiovascular function and the development of brain injury. Pediatr Res 2014;75:682-8.

11 Duley L, Dorling J, Pushpa-Rajah A, et al. Randomised trial of cord clamping and initial stabilisation at very preterm birth. Arch Dis Child Fetal Neonatal Ed 2018;103:F6-F14.

12 Katheria A, Poeltler D, Durham J, et al. Neonatal resuscitation with an intact cord: a randomized clinical trial. J Pediatr 2016;178:75-80.

13 Winter J, Kattwinkel J, Chisholm C, et al. Ventilation of preterm infants during delayed cord clamping (VentFirst): a pilot study of feasibility and safety. Am J Perinatol 2017:34:111-6.

14 Wyllie J, Bruinenberg J, Roehr CC, et al. European resuscitation council guidelines for resuscitation 2015: section 7. Resuscitation and support of transition of babies at birth. Resuscitation 2015;95:249-63.

15 Yao AC, Moinian M, Lind J. Distribution of blood between infant and placenta after birth. Lancet 1969;2:871-3.

16 Dawson JA, Kamlin CO, Wong C, et al. Changes in heart rate in the first minutes after birth. Arch Dis Child Fetal Neonatal Ed 2010;95:F177-81.
17 Brady JP, James LS. Heart rate changes in the fetus and newborn infant during labor, delivery, and the immediate neonatal period. Am J Obstet Gynecol 1962;84:1-12.

18 Phillipos E, Solevåg AL, Aziz K, et al. Oxygen saturation and heart rate ranges in very preterm infants requiring respiratory support at birth. $J$ Pediatr 2017; 182:41-6

19 Oei JL, Finer NN, Saugstad OD, et al. Outcomes of oxygen saturation targeting during delivery room stabilisation of preterm infants. Arch Dis Child Fetal Neonatal Ed 2018:103:F446-54.

20 Mian Q, Cheung PY, O'Reilly M, et al. Impact of delivered tidal volume on the occurrence of intraventricular haemorrhage in preterm infants during positive pressure ventilation in the delivery room. Arch Dis Child Fetal Neonatal Ed 2019;104:F57-62.

21 Lang JA, Pearson JT, Binder-Heschl C, et al. Increase in pulmonary blood flow at birth: role of oxygen and lung aeration. J Physiol 2016;594:1389-98.

22 Lang JA, Pearson JT, te Pas AB, et al. Ventilation/perfusion mismatch during lung aeration at birth. J App/ Physiol 2014;117:535-43.

23 Crossley KJ, Allison BJ, Polglase GR, et al. Dynamic changes in the direction of blood flow through the ductus arteriosus at birth. J Physiol 2009;587(Pt 19):4695-704

24 Hooper SB, Binder-Heschl C, Polglase GR, et al. The timing of umbilical cord clamping at birth: physiological considerations. Matern Health Neonatol Perinatol 2016;2:4.

25 Hooper SB, Te Pas AB, Polglase GR, et al. Animal models in neonatal resuscitation research: What can they teach us? Semin Fetal Neonatal Med 2018. doi: 10.1016/j. siny.2018.07.002. [Epub ahead of print 6 Jul 2018].

26 McDonald SJ, Middleton P, Dowswell T. Effect of timing of umbilical cord clamping of term infants on maternal and neonatal outcomes. Cochrane Database Syst Rev 2013;7:CD004074.

27 Tarnow-Mordi W, Morris J, Kirby A, et al. Delayed versus immediate cord clamping in preterm infants. N Engl J Med 2017:377:2445-55.

28 Mercer JS, Vohr BR, McGrath MM, et al. Delayed cord clamping in very preterm infants reduces the incidence of intraventricular hemorrhage and late-onset sepsis: a randomized, controlled trial. Pediatrics 2006;117:1235-42.

29 Mercer JS, McGrath MM, Hensman A, et al. Immediate and delayed cord clamping in infants born between 24 and 32 weeks: a pilot randomized controlled trial. J Perinatol 2003;23:466-72.

30 van Vonderen JJ, Hooper SB, Kroese JK, et al. Pulse oximetry measures a lower heart rate at birth compared with electrocardiography. J Pediatr 2015;166:49-53.

31 Kamlin CO, Dawson JA, O'Donnell CP, et al. Accuracy of pulse oximetry measurement of heart rate of newborn infants in the delivery room. J Pediatr 2008;152:756-60.

32 Dawson JA, Kamlin CO, Vento $\mathrm{M}$, et al. Defining the reference range for oxygen saturation for infants after birth. Pediatrics 2010;125:e1340-7. 